\title{
Exuberant Neuronal Convergence onto Reduced Taste Bud Targets with Preservation of Neural Specificity in Mice Overexpressing Neurotrophin in the Tongue Epithelium
}

\author{
Faisal N. Zaidi, ${ }^{1,2,3}$ Robin F. Krimm, ${ }^{5}$ and Mark C. Whitehead ${ }^{4}$ \\ ${ }^{1}$ Howard Hughes Medical Institute and Departments of ${ }^{2}$ Neurobiology, ${ }^{3}$ Neurosciences, and ${ }^{4}$ Surgery, University of California, San Diego, La Jolla, \\ California 92093, and ${ }^{5}$ Department of Anatomical Sciences and Neurobiology, University of Louisville School of Medicine, Louisville, Kentucky 49292
}

\begin{abstract}
A mouse fungiform taste bud is innervated by only four to five geniculate ganglion neurons; their peripheral fibers do not branch to other buds. We examined whether the degree or specificity of this exclusive innervation pattern is influenced by brain-derived neurotrophic factor (BDNF), a prominent lingual neurotrophin implicated in taste receptoneural development. Labeled ganglion cells were counted after injecting single buds with different color markers in BDNF-lingual-overexpressing (OE) mice. To evaluate the end-organs, taste buds and a class of putative taste receptor cells were counted from progeny of BDNF-OE mice crossbred with green fluorescent protein (GFP) (gustducin) transgenic mice. Fungiform bud numbers in BDNF-OE mice are 35\%, yet geniculate neuron numbers are $195 \%$, of wild-type mice. Neurons labeled by single-bud injections in BDNF-OE animals were increased fourfold versus controls. Injecting three buds, each with different color markers, resulted in predominantly single-labeled ganglion cells, a discrete innervation pattern similar to controls. Thus, hyper-innervation of BDNF-OE buds involves many neurons innervating single buds, not increased fiber branching. Therefore, both wild-type and BDNF-OE mice exhibit, in fungiform buds, the same, "discrete" receptoneural pattern, this despite dramatic neurotrophin overexpression-related decreases in bud numbers and increases in innervation density. Hyperinnervation did not affect GFP positive cell numbers; proportions of GFP cells in BDNF-OE buds were the same as in wild-type mice. Total numbers of ganglion cells innervating buds in transgenic mice are similar to controls; the density of taste input to the brain appears maintained despite dramatically reduced receptor organs and increased ganglion cells.
\end{abstract}

Key words: taste bud; geniculate; ganglion; innervation; mouse; neurotrophin

\section{Introduction}

A mouse fungiform taste bud receives innervation from only four to five geniculate ganglion neurons. Moreover, these neurons, although scattered in the ganglion, send unbranched fibers that converge selectively on a single bud (Zaidi and Whitehead, 2006). This exclusive receptoneural relationship is functionally significant. Whatever information a ganglion cell signals (e.g., a specific taste quality), it reflects the activation of a single bud. The molecular factors that direct the formation of these "bud units," as we have termed the mouse's discrete receptoneural arrangement, are unknown.

Growth factors and their molecular receptors appear critical for the establishment of the peripheral taste system. Brainderived neurotrophic factor (BDNF) and neurotrophin-3 (NT3), and their receptors, are expressed in taste bud-bearing lingual papillae and their innervating ganglion cells (Nosrat and Olson,

\footnotetext{
Received June 4, 2007; revised 0ct. 18, 2007; accepted 0ct. $28,2007$.

This work was supported by National Institutes of Health Grant R01 DC01091. We thank Dr. Charles S. Zuker for support and for helpful suggestions during this research.

Correspondence should be addressed to Dr. MarkC. Whitehead, Department of Surgery and Anatomy, University of California, San Diego, 9500 Gilman Drive, Mail Code 0604, La Jolla, CA 92093-0604. E-mail: mcwhitehead@ucsd.edu.

DOI:10.1523/JNEUROSCI.2517-07.2007

Copyright $\odot 2007$ Society for Neuroscience $\quad 0270-6474 / 07 / 2713875-07 \$ 15.00 / 0$
}

1995, 1998; Nosrat et al., 1996, 2000, 2001; Farbman et al., 2004). Gemmal and ganglion cell numbers are disrupted in the absence or overexpression of BDNF, or its receptor, tyrosine kinase $\mathrm{B}$ (TrkB) (Fritzsch et al., 1997; Nosrat et al., 1997; Cooper and Oakley, 1998; Oakley et al., 1998; Mistretta et al., 1999; Ringstedt et al., 1999; Krimm et al., 2001; Sun and Oakley, 2002). Thus, neurotrophins and their receptors influence, somehow, the development and maintenance of peripheral neural elements in taste as in other sensory systems (Schimmang et al., 1995; Fundin et al., 1997; Buckland and Cunningham, 1998; Caminos et al., 1999). Whether neurotrophins influence receptoneural connections has not been reported.

Because growth factors and their receptors affect both taste buds and taste ganglion neurons, these factors may influence, by their timing, location, or amount, the density or specificity of innervation of the peripheral end organ. The anterior tongue taste system in mouse is ideal for evaluating this because the normal receptoneural pattern is remarkably precise, more so than in other rodents whose ganglion cell peripheral fibers branch considerably (Miller, 1971, 1974; Whitehead et al., 1999; Zaidi and Whitehead, 2006). In the present study, the innervation pattern was examined in mice that overexpress BDNF in the lingual epithelium, both around taste buds and at filiform papillae (Krimm, 2001). These BDNF-overexpressing (OE) mice have a 
dramatically altered taste phenotype (i.e., one-third the number of fungiform taste buds and, paradoxically, twice normal numbers of geniculate ganglion cells) (Krimm, 2001). We hypothesize that with BDNF-OE, elevated numbers of neurons innervate fewer taste buds, and that the bud unit pattern of innervation could be disrupted by excess neurotrophin, for example, resulting in a degradation of the innervation specificity seen in wildtype mice. Innervation density and specificity were assessed in the present study.

We injected single taste buds of BDNF-OE mice with different color fluorescent markers to evaluate both the density and specificity of innervation. Counts of taste buds were performed to verify changes in the populations of receptor end organs. This was facilitated by cross breeding BDNF-OE mice with transgenic mice expressing green fluorescent protein (GFP) in receptor cells; their progeny expressing both phenotypes were evaluated. Counts of GFP cells evaluated whether innervation density influences receptor cell number.

\section{Materials and Methods}

Animals. Experimental animals consisted of C57BL/6J wild-type mice (The Jackson Laboratory, Bar Harbor, ME) and transgenic mice that overexpress BDNF under the control of a cytokeratin-14 promoter/enhancer (BDNF-OE) (LeMaster et al., 1999) aged 6-16 weeks. The transgenic mice have enhanced expression of BDNF in cells that express keratin 14 (K-14). In the tongue, K-14 cells predominate in the lingual epithelium, including cells that immediately surround the taste bud (Krimm et al., 2001). Thus, BDNF is increased in the entire peripheral field that includes the lingual taste bud targets of geniculate ganglion cells. Mice expressing GFP under the control of a G-13 promoter and, thus, exhibiting fluorescence in all gustducin positive cells (Huang et al., 1999 ) were used to assess this class of receptor cells. These animals were bred with BDNF-OE mice to obtain an F1 generation GFP/BDNF-OE mice. Mice were genotyped for the BDNF-OE transgene using slot blot analysis on DNA extracted from tail. All laboratory procedures were approved by the University of California at San Diego's Laboratory Animal Care and Use Committee and followed the National Institutes of Health Guide for the Care and Use of Laboratory Animals.

Dye preparation. Lipophilic dyes (Invitrogen, Eugene, OR) Fast DiI (D-3899; absorption, $568 \mathrm{~nm}$; emission, 598HQ40 nm), Fast DiO (D3898; absorption, $488 \mathrm{~nm}$; emission, 522/35 nm), Fast DiD (D-7757; absorption, $647 \mathrm{~nm}$; emission, 680DF32 nm) were dissolved at the concentration of $3-5 \mathrm{mg} / \mathrm{ml}$ in a solution (DMSO:ethanol, 1:1) (Fraser, 1996; Zaidi and Whitehead, 2006). One microliter of the dye solution was loaded into glass capillaries ( $25 \mu \mathrm{m}$ tip diameter) secured on the micromanipulator (Fine Science Tools, Foster City, CA).

Papillae labeling. Animals were anesthetized by intraperitoneal injection with Pentobarbital, $40 \mathrm{mg} / \mathrm{kg}$, after calming with Metofane vapors. Additional injections of pentobarbital $(10 \mathrm{mg} / \mathrm{k})$ were given as needed (approximately every $30 \mathrm{~min}$ ) to maintain deep surgical anesthesia. The animal was kept warm on a heating pad until it recovered from anesthesia. The tongue was gently pulled out of the mouth, immobilized by pressing against the sticky surface of double-sided tape attached to a small platform. Fungiform papillae were visualized by topical application of $0.5 \%$ Methylene Blue solution (Fisher Scientific, Houston, TX). With a surgical microscope (Zeiss, Oberkochen, Germany) and micropipette manipulator (Fine Science Tools), single taste papillae were selected and targeted with a glass pipette (100 $\mu \mathrm{m}$ tip diameter) for injection. The dye-filled capillary was lowered over the papilla and pressed snugly to cover and seal around the taste pore. Care was taken not to spill the dye onto the adjacent taste papillae. A cyclic current of $4 \mu \mathrm{Amp}$ with $5 \mathrm{~s}$ on-off pulses for 4-6 min (square anodal pulse) was passed (BAB-500 iotophoresis pump; Kation Scientific, Minneapolis, MN). The negative terminal of the current source was attached to the external ear of the animal. In cases where three dyes were injected, the different color dyes were used to label different near-neighbor papillae in the same preparation. In BDNF-OE mice some taste papillae are farther apart than in wild-type mice. In these animals we only injected papillae that were as close together as those in controls. All injected taste papillae were on the dorsal surface of the anterior tongue, within $5 \mathrm{~mm}$ of the tip and $0.5 \mathrm{~mm}$ or more from the midline.

Tissue histology, microscopy, and statistics. After a postinjection survival time of $48 \mathrm{~h}$, the animals were killed with a lethal injection of sodium pentobarbital and immediately perfused with $4 \%$ paraformaldehyde in PBS. Ganglia and tongues were removed and left in $4 \%$ paraformaldehyde for 1-3 h followed by PBS (ganglia) or 30\% sucrose incubation (tongues) overnight. Whole ganglia and $20-\mu \mathrm{m}$-thick frozen-cut sections of the tongues were examined under a confocal fluorescent microscope [Bio-Rad (Hercules, CA) MRC1024 with the confocal scan head on a Nikon (Tokyo, Japan) E800 upright microscope]. Each ganglion was mounted such that its ventral surface lay flat on the surface of the slide. The dorsoventral thickness of the ganglion was divided into 50 optical sections (along the $z$-axis). Each confocal section was scanned three times and the Kalman average of three such scans was collected through the entire thickness. Likewise, the same ganglion was imaged for other dyes by using the corresponding laser settings (without moving the ganglion or changing the scan parameters). Finally a transmission (bright field) image was also collected. Optical images thus obtained were exported into the Adobe (San Jose, CA) Photoshop software for their detailed analysis (see below). Three labeled ganglia were embedded, sectioned, and stained with the Nissl green reagent (Invitrogen) (neuronal cell marker) to confirm the identities of the dye filled cells. All labeled cells were found to be the neurons and not glia.

Counts of labeled ganglion cells were generally obtained bilaterally because injections of markers could be performed on both sides of the tongue; the innervation is unilateral. Thus, in quantifying ganglion cells, $n$ is the number of ganglia. In Results, regarding these counts, we also state numbers of animals. Tests of significant differences between wildtype and transgenic mice, for numbers of labeled ganglion cells and for numbers of GFP-positive receptor cells per bud (below), used the Student's $t$ test. A significance criterion of 0.01 was used.

In situ hybridization. TrkB expression in fungiform papillae was determined by mRNA labeling with a bright-field alkaline phosphatase method. Cryostat sections $(6-8 \mu \mathrm{m})$ of paraformaldehyde-fixed anterior tongue were digested with a $0.8 \%$ pepsin, $0.2 \mathrm{~N} \mathrm{HCl}$ solution at $37^{\circ} \mathrm{C}$. Tissue was rinsed and incubated with fluorescein-conjugated hybridization probe (TrkB oligo probe, GD1278-OP; Genedetect, Sarasota, FL) at $200 \mathrm{ng} / \mathrm{ml}$. After rinsing, sections were processed with an in situ hybridization (ISH) detection kit (K0607; DAKO, Carpinteria, CA), rinsed, and treated with anti-fluorescein alkaline phosphatase reagent. Finally, a BCIP/NBT (5-bromo-4-chloro-3-indoylphosphate-nitro blue tetrazolium) BCIP/NBT substrate solution (K0607; DAKO) was added to the sections, rendering the marker visible in transmitted light microscopy. Methodological controls for ISH included pretreating the sections with RNase (10 mg/ml) (Sigma, St. Louis, MO), excluding the probe from the hybridization buffer, or running sense probe. Quantification was accomplished using longitudinally sectioned papillae in which taste bud diameters and the thicknesses of TrkB-expressing nerve bundles at the base of buds could be measured. Measurements were taken only at the base of the buds to optimize the likelihood that the measured bundle contains fibers destined to innervate the bud and not the nontaste epithelium of the papillary region alongside the bud (Whitehead et al., 1985). Measurements were taken of the width of the bundle (i.e., encompassing the outermost TrkB positive fibers). The thinness of the sections and the curving of the fibers, especially in the transgenic cases, precluded counts of individual fibers. Two-way comparisons were tested using Student's $t$ test. For this quantification, $n$ is the number of buds/nerve bundles.

Image analysis. All 50 images (corresponding to one dye) were superimposed and flattened (along the $z$-axis) into one final image. This merged image was pseudocolored and overlapped (merged transparent) with other color images (corresponding to the two other dyes). DiIlabeled cells were colored red, $\mathrm{DiD}$ blue, and $\mathrm{DiO}$ green. Likewise confocal optical series of images were also analyzed along $x$ and $y$ axes. Colocalization of dyes in single neuron was affirmed by studying the merged images at all three dimensions (Zaidi and Whitehead, 2006).

Taste papillae maps and receptor cell counts. Mouse tongues, previously 

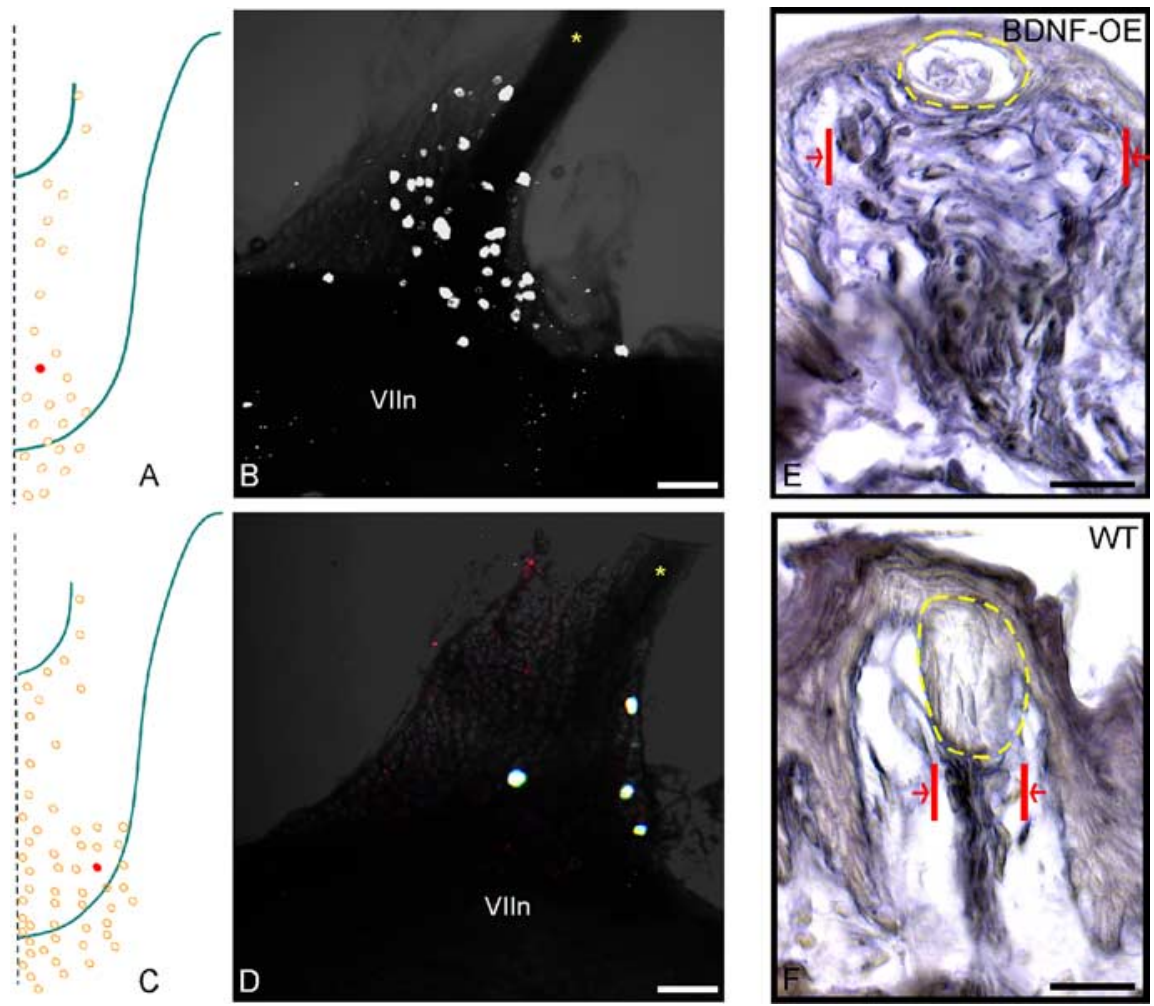

Figure 1. $A-D$, Labeled cells in the geniculate ganglion after injecting a single fungiform bud with Di0 are vastly more numerous in the BDNF-OE mouse $(\boldsymbol{A}, \boldsymbol{B})$ than in the wild-type mouse $(\boldsymbol{C}, \boldsymbol{D})$. $\boldsymbol{E}$, The average number of labeled cells in the geniculate ganglion after injecting single buds with DiO in BDNF-OE animals is four times the number in wild-type animals. $\boldsymbol{F}$, Bundles of TrkB-positive nerve fibers, measured at the base of the bud, are thicker for BDNF-0E than for wild-type mice (inset, red lines, diameter of TrkB-positive fiber bundle; BDNF-OE, bud from overexpressing mouse; WT, bud from wild-type mouse). Scale bars, $50 \mu \mathrm{m}$.

fixed with 4\% paraformaldehyde, were removed and stained with $0.5 \%$ methylene blue to enhance the visual contrast between the taste papillae and the surrounding filiform papillae. Stained tongues were then viewed under the surgical microscope (Zeiss) and maps of the distribution of taste papillae were drawn. The upper margin of the side of the intermolar eminence was chosen to be starting point with the end being the extreme tip of the tongue. Papillae at the underside of the tip were mapped separately by inverting the tongue. The GFP/BDNF-OE mice were used for the mapping of the GFP-positive taste bud cells. A fluorescent dissection microscope (Nikon SMZ1000) was used to visualize and count the GFP expressing cells. Based on the intensity of the GFP expression, dim and bright GFP-positive cells were typically present in most buds. These two types of GFP-positive cells were counted separately. For this quantification, $n$ is the number of buds; numbers of animals are also listed in Results. The same tongues were later stained with $0.5 \%$ methylene blue and recounted for the papillae numbers. Counts were conducted without experimenter knowledge of mouse genotype. The results between the two counts were consistent.

\section{Results}

\section{Single fungiform taste bud injections}

Fungiform papillae bearing taste buds in wild-type mice are arranged in linear arrays on the mouse tongue (Jung et al., 1999, 2004; Zaidi and Whitehead, 2006). A series of parallel columns and rows of bud-bearing fungiform papillae extends from the intermolar eminence anteriorly on each side of the tongue. Fungiform papillae in BDNF-OE mice are dramatically fewer in number; their arrangement is disordered compared with wildtype mice (Krimm et al., 2001) (see Fig. 4B). Buds are denser at the tip; columns and rows are less discernible. Injecting single taste buds in BDNF-OE mice resulted in many more labeled geniculate ganglion cells per injected bud than in wild-type mice (Fig. 1B,D). Counts of labeled ganglion cells established that there were four times more neurons labeled after single bud injections in transgenic compared with control mice (18.7 \pm 1.59 SEM, $n=27$ buds, 9 animals, vs $4.9 \pm 0.86$, SEM, $n=22$ buds, 14 animals; $p<0.01$ ) (Fig. $1 E$ ). For an independent measure of the increased innervation of single fungiform taste buds in BDNF-OE animals, we examined RNA expression of a molecular receptor for BDNF, TrkB. TrkB-positive fibers leading to fungiform taste buds were more numerous and comprised thicker bundles in fungiform papillae in $\mathrm{OE}$ animals compared with wild-type animals (Fig. 1E,F). Measurements of the bundles, delineated by the outermost TrkB positive fibers at the base of the buds, determined that the collections of fibers of BDNF-OE mice are 4 times wider than those of wild-type mice $(149 \pm 9.93 \mu \mathrm{m}, \mathrm{SEM}, n=10$, vs $39 \pm 6.83$ $\mu \mathrm{m}, \mathrm{SEM}, n=9 ; p<0.01$ ) (Fig. $1 F$ ).

\section{Multiple fungiform taste bud injections}

Three adjacent (i.e., closest) buds were injected to test whether the increased numbers of ganglion cells innervating a bud might result from excessive branching of neurons in BDNF-OE tongues and a disruption of the specific pattern of neuronreceptor end-organ "bud units" that characterize normal mice (Zaidi and Whitehead, 2006). Labeled ganglion cells after injecting three closely spaced buds in BDNF-OE tongues with three different colored dyes, rarely exhibited double-labeled cells, and almost never triple labeled cells (Fig. 2). This result resembles closely the "exclusive" innervation pattern seen in wild-type mice. Counts of single and multiply labeled cells established that the bad unit innervation pattern is not disrupted (Fig. 3). The predominance of single-labeled cells, the small proportion of double-labeled cells, and the rare triplelabeled cells were not different comparing BDNF-OE and wildtype mice ( $p=0.29,0.26$, and 0.86 , comparing proportions of single-, double-, and triple-labeled cells, respectively, of transgenic and wild-type mice; $n=9$ sites, 3 buds/site, 7 BDNF-OE animals; $n=5$ sites, 3 buds/site, 3 wild-type animals).

\section{Numbers of identified receptor cells}

Because fungiform taste buds in BDNF-OE animals were fewer in number and innervated by many more ganglion cells than control mice, we sought to determine whether the increased innervation was accompanied by changes in the numbers of GFP (gustducin-expressing) cells per bud (i.e., whether the potential synaptic partners of the fibers were correspondingly increased). To this end, counts were obtained of fluorescent cells in buds from GFP mice and GFP/BDNF-OE mice. In these animals, G-13 promoter drives GFP expression in all gustducin-positive cells (Huang et al., 1999). This promoter is a G-protein subunit and is expressed in a subset of cells in most taste buds. GFP/BDNF-OE mice had fewer buds with a disordered arrangement on the anterior tongue (Fig. 4, compare $A, B$ ), confirming the previously 
described OE phenotype (Krimm et al., 2001). In both GFP and GFP/BDNF-OE mice, approximately one-third of buds were devoid of fluorescent cells. However, the remaining buds contained one to five fluorescent cells (Fig. 4C,D). Fluorescent cells were of two intensities: bright and dim. Regarding bright cells, for both BDNF OE and control animals, buds with one fluorescent cell were more numerous than buds with two fluorescent cells, which, in turn, were more numerous than buds with three fluorescent cells, etc. (Fig. $4 E$ ). For dim cells the distribution was similar, although slightly right-shifted (Fig. $4 F$ ). There were no differences in distributions of GFP cells comparing control ( $n=589$ buds, 3 animals) with BDNF-OE mice ( $n=120$ buds, 3 animals) for bright cells $(p=0.18)$, dim cells $(p=0.61)$, or total cells $(p=0.27)$. Thus, hyperinnervation was not accompanied by a change in numbers of gustducin expressing taste bud cells.

\section{Discussion}

The key finding in the present study is that overexpression of BDNF in the lingual epithelium, which is characterized by an enlarged population of ganglion cells yet a markedly reduced number of taste buds, is associated with dramatically increased numbers of geniculate ganglion cells innervating the buds, but no disruption in the discrete pattern (bad unit) whereby unbranched nerve fibers converge onto single taste buds. The result of neurotrophin overexpression is a deployment of the normal number of ganglion cells to a markedly reduced population of peripheral target organs.

\section{Neurotrophins and innervation density}

The neurotrophin family of neuronal growth factors (e.g., NT4, BDNF, NGF), or their molecular receptors, have been shown in nongustatory sensory systems to influence peripheral innervation, for example, innervation of the inner ear by eighth nerve ganglion cells (Schimmang et al., 1995), and innervation of cutaneous receptors by dorsal root ganglion cells (Fundin et al., 1997; LeMaster et al., 1999). Neurotrophins also influence the central growth of connections from peripheral sensory receptors to the brain (Buckland and Cunningham, 1998; Caminos et al., 1999; Patel et al., 2003). Regarding a role for neurotrophins in peripheral innervation density by primary sensory nerves, BDNF-OE mice, in particular, exhibit greater than normal innervation of hair follicles. In these overexpressing animals, despite enhanced skin innervation, numbers of trigeminal and dorsal root ganglion cells are normal. In contrast, increased numbers of ganglion cells are seen in the nodose and geniculate ganglia (Krimm et al., 2001). This suggests a differential enhancement by peripheral BDNF on the numbers of some types of primary sensory neurons, but not others.

In the taste system, BDNF is expressed in mature fungiform taste buds (Ganchrow et al., 2003) and in developing fungiform papillae, possibly signaling the loci where bud primordia will form or where growing nerve fibers will terminate (Nosrat et al., $200,2001)$. However, overexpression of lingual epithelial BDNF is disruptive in some manner leading to a dramatic, 65\% reduction of fungiform taste buds on the tongue (Krimm et al., 2001). At the same time, there is a near doubling of geniculate ganglion neuron numbers (93\% increase) and an approximate $50 \%$ increase in average neuron size. The taste bud losses, along with increased numbers of ganglion cells in BDNF-OE animals, suggest a dramatic alteration in some aspect of gustatory innervation. In previous work with these transgenic animals, abnormally large nerve bundles appeared to end below the epithelium within the tongue musculature (Krimm et al., 2001; Lopez and Krimm, 2006). It was not clear from the previous studies what the status is of the fibers innervating fungiform papillae. The innervation of taste buds, per se, was not evaluated previously. The present results demonstrate that the remaining fungiform taste buds are innervated in BDNF-OE mice by geniculate neurons, and that the innervation is four times as dense as that of buds from wild-type mice. 


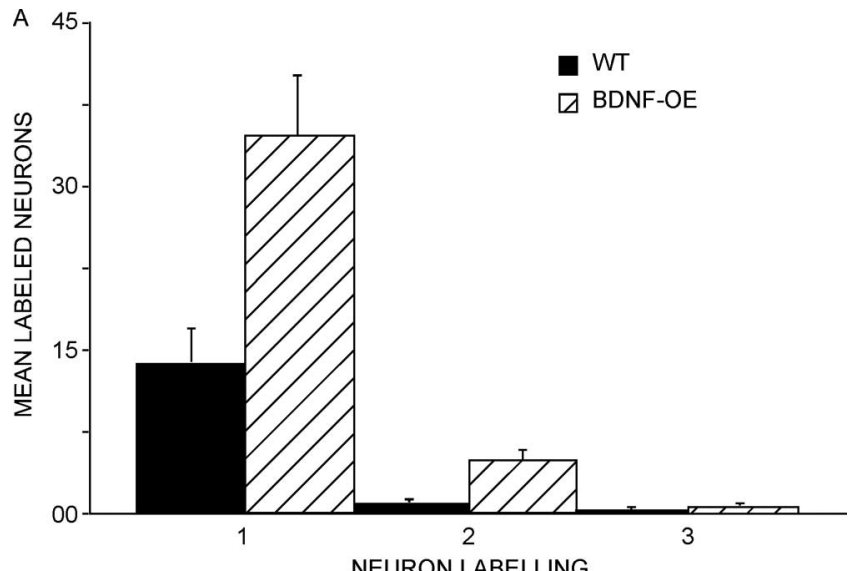

NEURON LABELLING

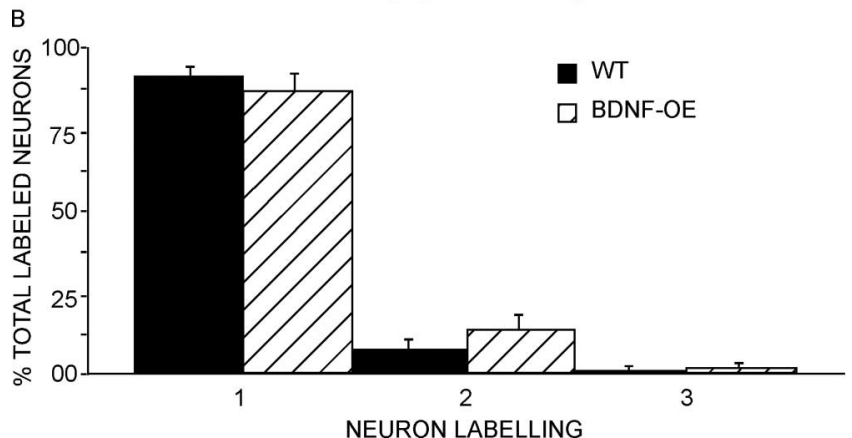

Figure 3. A, Average number of single-labeled ganglion cells (1), in both BDNF-OE and wild-type mice, vastly outnumber double-labeled cells (2) after injecting three adjacent fungiform buds with different color dyes. Triple-labeled cells (3) are extremely rare. $\boldsymbol{B}$, Same data as in $\boldsymbol{A}$ showing the percentage of all labeled cells containing one, two, or three markers. There were no significant differences between BDNF-0E and wild-type mice comparing proportions of single-, double-, or triple-labeled cells.

Hyperinnervation in BDNF-OE mice of glabrous, but not hairy, skin is associated with increases in the number of innervated Merkel cells (Botchkarev et al., 1999; LeMaster et al., 1999). Also, Meissner's corpuscles are larger in BDNF-OE mice. Such an increase in numbers of gustducin positive, putative receptor cells was not observed in the taste system. Numbers of fluorescent receptor cells in fungiform taste buds of GFP and GFP/BDNF-OE mice were equivalent. Thus, the influence of increased innervation on numbers of end-organ receptors is not consistent across sensory field types. The increased innervation does not "instruct" or "permit" more numerous potential synaptic partners (i.e., in this case, gustducin-expressing receptor cells). Previous study of rat show a correlation between taste bud size and number of innervating geniculate ganglion cells (Krimm and Hill, 2000); bigger buds presumably contain more cells than smaller ones. Surprisingly, in fungiform taste buds in the present system, increased innervation density, per se, is not accompanied by an increased number of putative receptor cells, at least not of those that express gustducin.

In both GFP and GFP/BDNF-OE mice, only a subset of cells in the buds were fluorescent. Indeed, as shown in Figure 4, approximately one-third of buds are devoid of fluorescent cells. This is partly attributable to the fact that gustducin-expressing cells do not represent all the classes of receptor cells. Additionally, taste bud cells are dynamic; the number and degree of differentiation of individual cell types vary from bud to bud, and over time. Thus, an identified bud that appears devoid of GFP cells on one day, if identified because of its unique location (by row and col- umn) and re-examined a week later will often contain one or more fluorescent cells (our unpublished observation).

\section{Neurotrophins and innervation specificity}

Taste buds on the anterior tongue of mice have an exclusive relationship with ganglionic neurons. Small groups of neurons (five cells, on the average), scattered in the geniculate ganglion, selectively innervate single buds; collaterals to adjacent buds are rare (Zaidi and Whitehead, 2006). This innervation pattern is considerably more discrete than that of other rodents (e.g., rat and hamster) (Miller, 1971, 1974; Whitehead et al., 1999), as verified in two rodent species with the present dye labeling method and discussed previously (Zaidi and Whitehead, 2006). Molecular factors that account for this receptoneural specificity, and the significance of this arrangement for taste function are unknown. Neurotrophins in target tissues are well known to stimulate the growth of peripheral fibers of innervating neurons. Their role in the fine-tuning of innervation patterns is uncertain. BDNF overexpression in skin leads to increased density of innervation, yet numbers of sensory ganglion cells are unchanged (Albers et al., 1996). This suggests neurotrophin-related increased peripheral branching of ganglion cells in the somatosensory system. The present results establish that increased peripheral BDNF is associated with massive increases in the density of taste bud innervation, yet the pattern of innervation is remarkably unchanged in the transgenic mouse. Thus, BDNF in the anterior tongue affects the degree, but not the specificity of peripheral innervation. Presumably other factors, as yet unknown, that function apart from and are unaffected by BDNF levels, account for the discrete nature of the "bud units." The excessive innervation of buds in BDNF-OE animals results from a deployment of more neurons to single buds, not increased branching of fibers to more buds than normal; thus, the bad unit gets bigger.

The numbers of taste buds and ganglion cells in wild-type and BDNF-OE mice suggest a compensatory equilibration between the two as a consequence of the altered phenotype. Wild-type mice have $\sim 47$ fungiform buds per side of the tongue (Krimm, 2001 ) and BDNF-OE mice have $\sim 13$. Wild-type mouse geniculate ganglion neurons number 873 and BDNF-OE mouse neurons number 1684. With five neurons exclusively innervating each bud in wild-type mice (Zaidi and Whitehead, 2006), we calculate that $\sim 250$ ganglion cells normally supply the fungiform buds unilaterally; the remaining 523 cells innervate palatal buds and supply general sensory innervation to ear epithelium (Bosman, 1978; Whitehead and Frank, 1983). Because 20 neurons, on average, exclusively innervate each of $\sim 13$ buds in BDNF-OE mice, 260 cells supply fungiform buds per tongue side, a nearly identical number to that for wild-type mice. Thus, the innervation from the population of ganglion cells that function in anterior tongue taste appears to deploy evenly among the smaller pool of target buds in the transgenic mouse. The 1424 remaining geniculate ganglion cells in BDNF-OE mice are unaccounted for in terms of their targets. Some innervate palatal buds. Some, perhaps an excessive number, innervate the ear epithelium, a possible additional consequence of BDNF overexpression. In addition, we cannot rule out the possibility that some of the excess neurons innervate lingual tissues other than taste buds (i.e., nongustatory tissues deep in the tongue), as suggested by the nerve labeling experiments of Krimm et al. (2001) (see also, Lopez and Krimm, 2006). Finally, it is possible that nontaste ganglionic neurons, in particular, have proliferated excessively in the BDNF-OE animal. 

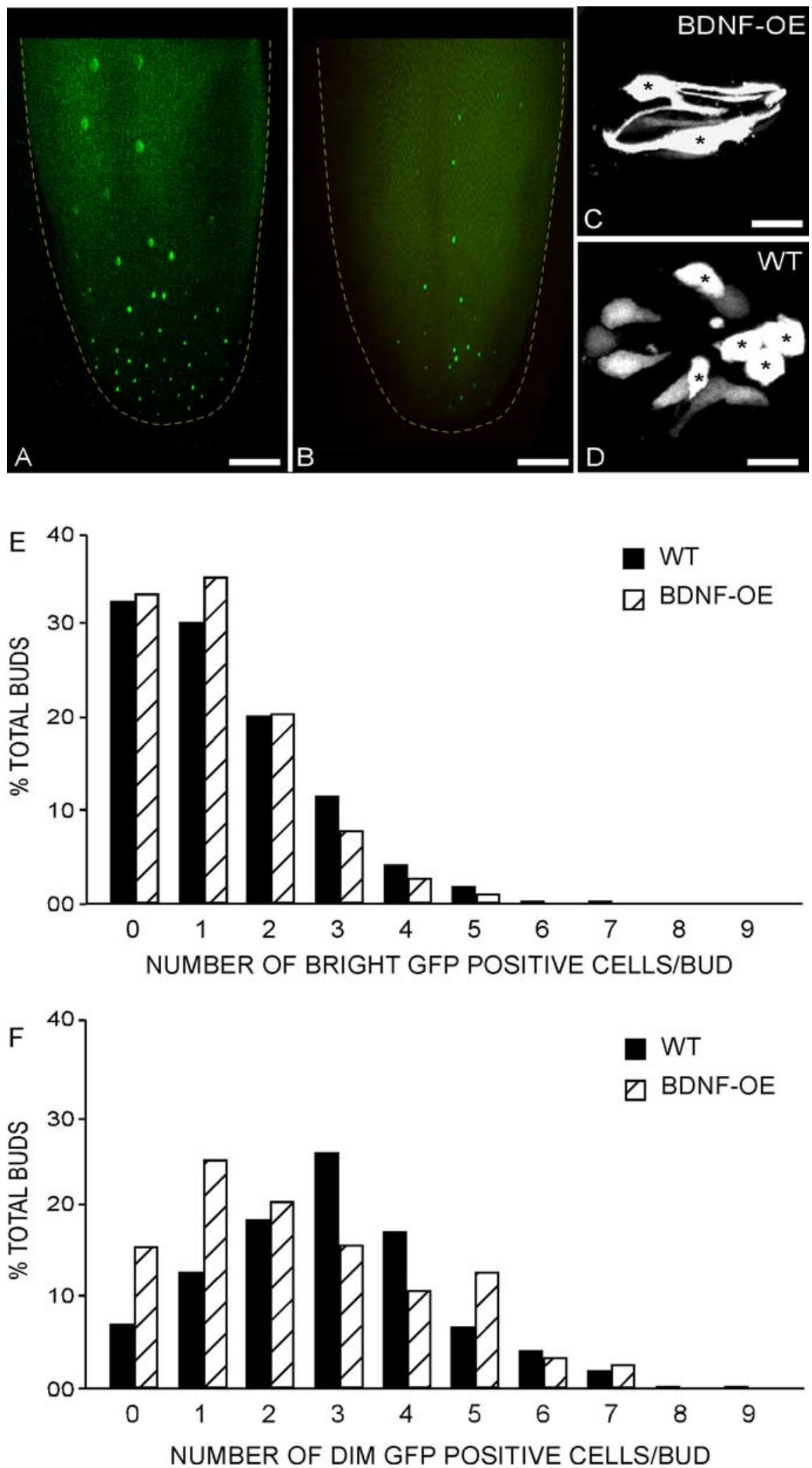

Figure 4. Distribution and number of fluorescent receptor cells in taste buds on the anterior tongues of GFP mice and GFP/ BDNF-OE mice. $\boldsymbol{A}$, Fluorescent cell-containing buds in GFP mice are arranged in linear arrays on the tongue. $\boldsymbol{B}$, Fluorescent buds are fewer and the normal linear arrangement is not apparent in GFP/BDNF-OE mice. $\boldsymbol{C}, \boldsymbol{D}$, High-magnification view of GFP-positive cells from GFP/BDNF-OE and GFP wild-type (WT) buds, respectively. In these examples, buds of both types of mice contain both brightly $\left({ }^{*}\right)$ and dimly fluorescent cells. The bud in $\boldsymbol{C}$ is seen in longitudinal view (i.e., from the side). The bud in $\boldsymbol{D}$ is viewed from the top of the bud (i.e., through the pore that overlies the central region where the cells converge apically). $\boldsymbol{E}$, Proportions of fungiform buds containing 0 , 1, 2, etc., brightly fluorescent, or dimly fluorescent $(\boldsymbol{F})$ cells per bud are similar for tongues from GFP and GFP/BDNF-OE mice.

\section{References}

Albers KM, Perrone TN, Goodman TP, Jones ME, Green MA, Davis BM (1996) Cutaneous overexpression of NT-3 increases sensory and sympathetic neuron number and enhances touch dome and hair follicle innervation. J Cell Biol 134:487-497.

Buckland ME, Cunningham AM (1998) Alterations in the neurotrophic factors BDNF, GDNF and CNTF in the regenerating olfactory system. Ann NY Acad Sci 855:260-265.

Bosman DH (1978) The distribution of the chorda tympani in the middle ear area in man and two other primates. J Anat 127:443-445.

Botchkarev VA, Kief S, Paus R, Moll I (1999) Overexpression of brain-derived neurotrophic factor increases Merkel cell number in murine skin. J Invest Dermatol 113:691-692.

Caminos E, Becker E, Martín-Zanca D, Vecino E (1999) Neurotrophins and their receptors in the tench retina during optic nerve regeneration. J Comp Neurol 404:321-331.

Carette MJM, Lane EB, Ferguson MWJ (1991) Differentiation of mouse embryonic palatal epithelium in culture: selective cytokeratin expression distinguishes between oral, medial edge and nasal epithelial cells. Differentiation 47:149-161.

Cooper D, Oakley B (1998) Functional redundancy and gustatory development in bdnf null mutant mice. Dev Brain Res 105:79-84.

Cui X-M, Shiomi N, Chen J, Saito T, Yamamoto T, Ito Y, Bringas P, Chai Y, Shuler CF (2005) Overexpression of Smad2 in Tgf- $\beta 3$-null mutant mice rescues cleft palate. Dev Biol 278:193-202.

Das I, Sparrow JR, Lin MI, Shih E, Mikawa T, Hempstead BL (2000) Trk C signaling is required for retinal progenitor cell proliferation. J Neurosci 20:2887-2895.

Farbman AI, Guagliardo N, Sollers SI, Hill DL (2004) Each sensory nerve arising from the geniculate ganglion expresses a unique fingerprint of neurotrophin and neurotrophin receptor genes. J Neurosci Res 78:659-667.

Fraser SE (1996) Iontophoretic dye labeling of embryonic cells. Methods Cell Biol 51:147-160.

Fritzsch B, Sarai PA, Barbacid M, Silos-Santiago I (1997) Mice with a targeted disruption of the neurotrophin receptor trkB lose their gustatory ganglion cells early but do develop taste buds. Int J Dev Neurosci 15:563-576.

Fundin BT, Silos-Santiago I, Ernfors P, Fagan AM Aldskogius H, DeChiara TM, Phillips HS, Barbacid M, Yancopoulos GD, Rice FL (1997) Differential dependency of cutaneous mechanoreceptors on neurotrophins, trk receptors, and P75 LNGFR. Dev Biol 190:94-116.

Ganchrow D, Ganchrow JR, Verdin-Alczar M, Whitehead MC (2003) Brain-derived neurotrophic factor-, neurotrphin-3-, and tyrosine kinase receptor-like immunoreactivity in lingual taste bud fields of mature hamster. J Comp Neurol 455:11-24.

Huang L, Shanker YG, Dubauskaite J, Zheng JZ, Yan W, Rosenzweig S, Spielman AI, Max M, Margolskee RF (1999) Ggamma13 colocalizes with gustucin in taste receptor cells and mediates IP3 responses to bitter denatonium. Nat Neurosci 12:1055-1062.

Jung HS, Oropeza V, Thesleff I (1999) Shh, 
Bmp-2, Bmp-4 and Fgf- 8 are associated with initiation and patterning. Mech Dev 81:179-182.

Jung HS, Akita K, Kim JY (2004) Spacing patterns on tongue surfacegustatory papilla. Int J Dev Biol 48:157-161.

Krimm RF, Hill DL (2000) Neuron/target matching between chorda tympani neurons and taste buds during postnatal rat development. J Neurobiol 43:98-106.

Krimm RF, Miller KK, Kitzman PH, Davis BM, Albers KM (2001) Epithelial overexpression of BDNF or NT4 disrupts targeting of taste neurons that innervate the anterior tongue. Dev Biol 232:508-521.

LeMaster AM, Krimm RF, Davis BM, Noel T, Forbes ME, Johnson JE, Albers KM (1999) Overexpression of brain-derived neurotrophic factor enhances sensory innervation and selectively increases neuron number. J Neurosci 19:5919-5931.

Lindsay RM (1996) Role of neurotrophins and trk receptors in the development and maintenance of sensory neurons: an overview. Philos Trans R Soc Lond B Biol Sci 351:365-373.

Lopez GF, Krimm RF (2006) Epithelial overexpression of BDNF and NT4 produces distinct gustatory axon morphologies that disrupt initial targeting. Dev Biol 292:457-468.

Miller IJ (1971) Peripheral interactions among single papilla inputs to gustatory nerve fibers. J Gen Physiol 37:1-24.

Miller IJ (1974) Branched chorda tympani neurons and interactions among taste receptors. J Comp Neurol 1558:155-166.

Mistretta CM, Goosens KA, Farinas I, LF Reichardt (1999) Alterations in size, number, and morphology of gustatory papillae and taste buds in BDNF null mutant mice demonstrate neural dependence of developing taste organs. J Comp Neurol 409:13-24.

Oakley B, Brandemihl A, Cooper D, Lau D, Lawton A, Zhang C (1998) The morphogenesis of mouse vallate gustatory epithelium and taste buds requires BDNF-dependent taste neurons. Dev Brain Res 105:85-96.

Nosrat CA (1997) Neurotrophins in the development of the gustatory system and teeth. $\mathrm{PhD}$ thesis, Karolinska Institute Stockholm, Sweden.

Nosrat CA, Olson L (1995) Brain-derived neurotrophic factor mRNA is expressed in the developing taste bud-bearing tongue papillae of rat. J Comp Neurol 360:698-704.

Nosrat CA, Olson L (1998) Changes in neurotrophin 3 mRNA expression patterns in the prenatal rat tongue suggest guidance of developing somatosensory nerves to their final targets. Cell Tissue Res 292:619-623.

Nosrat CA, Ebendal T, Olson L (1996) Differential expression of brainderived neurotrophic factor and neurotrophin 3 mRNA in lingual papil- lae and taste buds indicates roles in gustatory and somatosensory innervation. J Comp Neurol 376:587-602.

Nosrat CA, MacCallum DK, Mistretta CM (2001) Distinctive spatiotemporal expression patterns for neurotrophins develop in gustatory papillae and lingual tissues in embryonic tongue organ cultures. Cell Tissue Res 303:35-45.

Nosrat IV, Lindskog S, Seiger Å, Nosrat CA (2000) Lingual BDNF and NT-3 mRNA expression patterns and their relation to innervation in the human tongue: similarities and differences compared with rodents. J Comp Neurol 417:133-152.

Pan M, Naftel JP, Wheeler EF (2000) Effects of deprivation of neonatal nerve growth factor on the expression of neurotrophin receptors and brain-derived neurotropic factor by dental pulp afferents of the adult rat. Arch Oral Biol 45:387-399.

Patel TD, Kramer I, Kucera J, Niederkofler V, Jessel TM, Arber S, Snider WD (2003) Peripheral NT3 signaling is required for ETS protein expression and central patterning of proprioceptive sensory afferents. Neuron 38:403-416.

Ringstedt T, Ibáñez CF, Nosrat CA (1999) Role of brain-derived neurotrophic factor in target invasion in the gustatory system. J Neurosci 19:3507-3518.

Schimmang T, Minichiello L, Vazquez E, San Jose I, Giraldez F, Klein R, Represa J (1995) Developing inner ear sensory neurons require TrkB and TrkC receptors for innervation of their peripheral targets. Development 121:3381-3391.

Sun H, Oakley B (2002) Development of the anterior gustatory epithelia in the palate and tongue requires epidermal growth factor receptor. Dev Bio 242:31-43.

Tucker KL, Meyer M, Barde YA (2001) Neurotrophins are required for nerve growth during development. Nat Neurosci 4:29-37.

Whitehead MC, Frank ME (1983) Anatomy of the gustatory system in the hamster: central projections of the chorda tympani and the lingual nerve. J Comp Neurol 220:378-395.

Whitehead MC, Beeman C, Kinsella B (1985) Sensory endings of taste and general sensory nerves in fungiform papillae of the hamster. Am J Anat 173:185-201.

Whitehead MC, Ganchrow JR, Ganchrow D, Yao B (1999) Organization of geniculate and trigeminal ganglion cells innervating single fungiform taste papillae: a study with tetramethylrhodamine dextranamine labeling. Neuroscience 93:931-941.

Zaidi FN, Whitehead MC (2006) Discrete innervation of murine taste buds by peripheral taste neurons. J Neurosci 26:8243-8253. 